\title{
Association Between Plasma Aldosterone and Sleep Apneas in Arterial Hypertension
}

\author{
Asociación entre aldosterona plasmática y apneas del sueño en hipertensión arterial
}

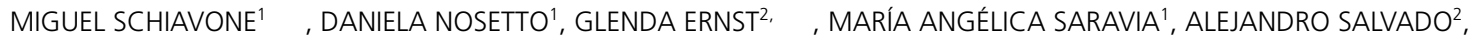 \\ HORACIO AVACA ${ }^{1}$, EDUARDO BORSINI² (D
}

\begin{abstract}
Background: Hypertension and obstructive sleep apneas and hypopneas are highly prevalent, frequently associated diseases, mainly in patients with resistant hypertension. In these patients, aldosterone levels correlate with obstructive sleep apnea severity and its blockade reduces seriousness. It has been reported that obstructive sleep apnea could intensify aldosterone secretion and this could be one of the mechanisms that increase blood pressure. However, there is little evidence demonstrating its relationship with the severity of obstructive sleep apnea in the population with suspected hypertension.

Objective: The aim of this study was to establish the association between plasma aldosterone and obstructive sleep apnea in patients with suspected hypertension without pharmacological treatment.

Methods: This was a prospective, descriptive observational study. Hypertension was diagnosed by ambulatory monitoring of blood pressure. The clinical suspicion of obstructive sleep apnea was evaluated by self-administered home respiratory polygraphy and severity was defined according to the apnea-hypopnea index per registry hour. Plasma aldosterone was assessed from a morning blood sample in the same evaluation session.

Results: A total of 109 patients were included in the study. Baseline aldosterone was higher in patients with obstructive sleep apnea independently of whether they were or not hypertensive $(\mathrm{p}<0.05)$. A stepwise aldosterone increase was found as obstructive sleep apnea was more severe in normotensive patients $(\mathrm{p}<0.05)$, while in the hypertensive group, the same pattern was found, but without significant differences.

Conclusion: A proportional increase in aldosterone, blood glucose and cardiovascular risk was found with increased sleep apnea severity.
\end{abstract}

Key words: Hypertension - Aldosterone - Sleep Apnea Syndromes

\section{RESUMEN}

Introducción: La hipertensión arterial y las apneas e hipopneas obstructivas del sueño son patologías de alta prevalencia frecuentemente relacionadas, fundamentalmente en pacientes con hipertensión arterial resistente. En los pacientes con esta afección, los niveles de aldosterona se correlacionan con la gravedad de la apnea obstructiva del sueño y su bloqueo reduce la gravedad. Se ha afirmado que la apnea obstructiva del sueño podría aumentar la secreción de esta hormona y que este podría llegar a ser uno de los mecanismos involucrados en el aumento de la presión arterial. Sin embargo, poca evidencia demuestra su relación con la gravedad de la apnea obstructiva del sueño en la población con sospecha de hipertensión arterial.

Objetivo: determinar la asociación entre aldosterona plasmática y la apnea obstructiva del sueño en pacientes con sospecha de hipertensión arterial sin tratamiento farmacológico.

Material y método: Se diseñó un estudio prospectivo, observacional y descriptivo. El diagnóstico de hipertensión arterial se realizó mediante monitoreo ambulatorio de la presión arterial. La sospecha clínica de apnea obstructiva del sueño fue evaluada mediante poligrafía respiratoria domiciliaria autoadministrada y se definió gravedad según el índice de apneas e hipopneas por hora de registro. La medición de aldosterona plasmática se realizó en una extracción matinal en la misma evaluación.

Resultados: Se incluyeron 109 pacientes. La apnea obstructiva del sueño presentó mayor nivel basal de aldosterona independientemente que fuesen o no hipertensos $(\mathrm{p}<0,05)$ y existió un incremento escalonado a medida que aumentaba la gravedad de la apnea obstructiva del sueño en pacientes normotensos $(p<0,05)$, mientras que, en el grupo de hipertensión arterial, se halló el mismo patrón, pero sin diferencias significativas.

Conclusión: Se pudo observar un aumento proporcional de los valores de aldosterona, glucemia y riesgo cardiovascular a medida que se incrementaba la gravedad de la apnea del sueño.

Palabras clave: Hipertensión - Aldosterona - Síndromes de la apnea del sueño

REv ARGENT CARDIOL 2020;88:322-328. http://dx.doi.org/10.7775/rac.v88.i4.17720

Received: 04/22/2020 - Accepted: 06-24-2020

Address for reprints: Dr. Miguel Schiavone - Hospital Británico de Buenos Aires Servicio de Cardiología, Centro de Hipertensión Arterial - Solís 2184 C1134 ADT, CABA - E-mail: mjschiavone@gmail.com - Tel: 0054-11- 43096520

\footnotetext{
${ }^{1}$ Arterial Hypertension Center, Department of Cardiology, Hospital Británico de Buenos Aires

${ }^{2}$ Respiratory Medicine Center. Hospital Británico de Buenos Aires, Argentina.
} 


\section{Abbreviations}

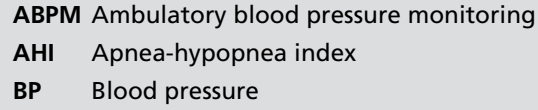

\section{INTRODUCTION}

Hypertension (HTN) and obstructive sleep apnea-hypopnea (OSA) are highly prevalent, frequently associated diseases, mainly in patients with resistant HTN. (1-3)

Hypertension affects $36 \%$ of the adult population and its lack of control or treatment leads to cardiovascular disease, heart failure, acute myocardial infarction, kidney failure and stroke after years of exposure. (4)

Obstructive sleep apnea-hypopnea is an emerging health issue, affecting more than $15 \%$ of men and more than $10 \%$ women in the total adult population, (5) and it is associated with morbidity and mortality attributable to traffic, labor and domestic accidents and the development of cardiovascular and cerebrovascular complications. $(6,7)$

It has been reported that patients with sleep apneas have hypercapnic and hypoxemic episodes secondary to the development of respiratory events. These phenomena generate sympathetic nervous system activation with subsequent increased release of serum catecholamines and, consequently, heart rate and blood pressure (BP) elevation by a mechanism of reflex vasoconstriction. (8) Other triggers are the proinflammatory effect, increased oxidative stress and increased vascular stiffness. (9)

Its severity assessed through the apnea-hypopnea index (AHI) is accompanied by changes in cardiovascular parameters, mainly $\mathrm{BP}$ and heart rate oscillations. (10-12) One of the cardiovascular regulatory systems affected by OSA is the baroreflex mechanism. This would alter chemoreflex activation secondary to intermittent hypoxia, contributing to acute and chronic BP increase. (13-15) It has been observed that only two weeks of nocturnal intermittent hypoxemia in patients without associated disease could increase systolic and diastolic BP by $8 \mathrm{mmHg}$ and $5 \mathrm{mmHg}$, respectively. $(15,16)$

Data from our country describe that approximately $50 \%$ of individuals with OSA are hypertensive (17, 18 ) and that $44 \%$ of hypertensive patients referred to specialized cardiological consultation had moderate to severe sleep apneas and were candidates for treatment with continuous positive airway pressure (CPAP). (19)

There is a dose-effect relationship between HTN and OSA severity, and for each event/h of AHI increase, there is the possibility of a $1 \%$ rise in the development of HTN. $(16,20-22)$

Occult HTN is underestimated in patients with OSA, and this is often revealed by 24-hour ambulatory blood pressure monitoring (ABPM) in $42 \%$ to $80 \%$ of
CPAP Continuous positive airway pressure

HT Hypertension

OSA Obstructive sleep apneas and hypopneas

cases. $(16,22-24)$

Numerous studies demonstrate that subjects with moderate-severe OSA (AHI >15 events/h) have more probability of being hypertensive than subjects of similar age and body weight, but without OSA. (16) In the Wisconsin Sleep Cohort Study, normotensive subjects with moderate-severe OSA tripled the risk of developing HTN during a 4-year follow-up compared with patients without OSA. (16) In addition, it has been observed that the greater the OSA severity, the higher the number and dose of anti-hypertensive drugs required to achieve the same BP control than in patients with less severe OSA. (16)

Continuous positive airway pressure treatment has shown consistent though modest antihypertensive benefit, with wide difference in response from one patient to another, and with greater benefit in severe OSA, higher BP levels and device use adherence. $(16,20)$ Although improvement in $\mathrm{BP}$ values varies in the range of $-2 \mathrm{mmHg}$, small interventional trials suggest that chronic CPAP use reduces the sustained activity of the sympathetic system and improves the baroreflex function and proinflammatory state, thus decreasing cardiovascular risk. $(13,16,20)$

Conversely, in patients with resistant HTN, aldosterone levels correlate with OSA severity and its blockade reduces seriousness. (16) Obstructive sleep apnea-hypopnea could increase this hormone and this could be one of the mechanisms involved in enhanced BP. (25) In a prospective study including 114 patients with resistant HTN, those with elevated risk of OSA reported greater 24-hour excretion of urinary aldosterone using the Berlin questionnaire. (20)

Two possibilities have been posed: that OSA stimulates aldosterone release or that excess aldosterone worsens preexistent OSA, although lack of a constant CPAP effect on aldosterone levels in several studies seems a contradictory argument. (20) However, clinical data document the opposite effect, i.e. excess aldosterone worsens OSA severity, since spironolactone (aldosterone antagonist) decreases moderate-severe OSA seriousness. $(21,27,28)$ In this sense, some authors have proposed the caudo-rostral fluid redistribution phenomenon as a mechanism linking the genesis of sleep apnea in hypertensive patients through the increase in the collapsibility of the upper airway. (26)

Based on the above, there is a relationship between plasma aldosterone and OSA, and most scientific evidence has been obtained from populations with resistant HTN. Therefore, the objective of the present study was to assess aldosterone levels in patients with suspected HTN and risk of OSA referred to a specialized 
center before receiving pharmacological treatment and to establish its relationship with OSA severity.

\section{METHODS}

This was a prospective, observational and descriptive study in adult patients with suspected HTN and untreated OSA at the time of consultation.

The following criteria had to be fulfilled for inclusion in the study: patients older than 18 years evaluated at the Arterial Hypertension Center of Hospital Británico of Buenos Aires between January and October 2017 with suspected HTN untreated at the time of inclusion.

A 24-hour ABPM registry was systematically performed to confirm the diagnosis of HTN as well as a nocturnal home respiratory polygraphy registry.

Routine blood tests included plasma aldosterone assessment, plasma renin activity and calculation of the aldosterone/renin ratio.

Aldosterone and renin were measured from a fasting baseline morning blood sample after supine rest for at least 30 minutes. Blood samples were then processed in situ by radioimmunoassay.

Exclusion criteria were prior known diagnosis of primary hyperaldosteronism, antihypertensive pharmacological treatment, contraindication to perform ABPM, need for urgent pharmacological treatment, uncontrolled diabetes, known moderate to severe chronic obstructive pulmonary disease, prior treatment with CPAP, acute or chronic heart failure, moderate to severe kidney failure, impossibility or intolerance to perform a respiratory polygraphy, uncontrolled thyroid disease and complete suppression of plasma renin activity.

Office BP was assessed following national and international guidelines $(29,30)$ with an automatic arm blood pressure monitor (OMRON 7220). Three measurement were taken separated by 2 minutes each, discarding the first one and considering the average between the last two.

A Spacelabs Ultralite device (model 90217, SpaceLabs, Redmond, WA) was used for ABPM. The device was programmed to assess BP every 15 minutes during daytime (8:00 a.m. to 11:00 p.m.) and every 30 minutes during nighttime (11:00 p.m. to 8:00 a.m.), and then adjusted to the patient's diary. Normotension was defined as daytime and nighttime $\mathrm{BP} \leq 135 / 85 \mathrm{mmHg}$ and $120 / 70 \mathrm{mmHg}$, respectively. Ambulatory blood pressure monitoring and respiratory polygraphy were performed on successive nights.

Respiratory polygraphy was done with a 5-channel Apnea Link Plus ${ }^{\mathrm{TM}}$ (ResMed, Australia) device with three basic signals: pulse oximetry, airflow by nasal cannula and thoracic effort (level III devices of the American Academy of Sleep Medicine). (31) Only registries with a total recording time in the manual analysis $>240 \mathrm{~min}(>4 \mathrm{~h}$ ) were accepted as valid. Apnea was defined as airway flow reduction above $80 \%$ from baseline for $\geq 10 \mathrm{~s}$ and hypopneas were considered as $50 \%$ airway flow reduction for $\geq 10 \mathrm{~s}$ associated with desaturations $\geq 3 \%$. The AHI was calculated as number of apneas/ hypopneas per hour of valid evaluation and is expressed as events per hour (ev/h). (32) Patients were classified as: NonOSA (AHI $<5 \mathrm{ev} / \mathrm{h})$, mild OSA (AHI $\geq 5.1$ and $<15 \mathrm{ev} / \mathrm{h})$ and moderate-severe OSA (AHI $\geq 15 \mathrm{ev} / \mathrm{h}$ ).

According to study results, patients were classified in 6 categories:

Normotensive without OSA (GI Non-HTN) with AHI $<5$ ev/h.

Normotensive with mild OSA (GII Non-HTN) with AHI between 5.1 and $15 \mathrm{ev} / \mathrm{h}$.

Normotensive with moderate-severe OSA (GIII NonHTN) with AHI > 15 ev/h-

Hypertensive without OSA (GI HTN) with AHI $<5$ ev/h.

Hypertensive with mild OSA (GII HTN) with AHI between 5.1 and $15 \mathrm{ev} / \mathrm{h}$.

Hypertensive with moderate-severe OSA (GIII HTN) with $\mathrm{AHI}>15 \mathrm{ev} / \mathrm{h}-$

\section{Statistical analysis}

Results were expressed as percentage for categorical variables or mean and standard deviation for numerical variables. Variables with normal distribution were expressed as mean and standard deviation, and those with non-normal distribution as mean and percentile (25\%-75\%). Fisher, Kruskal Wallis and Dunn's multiple comparisons tests were used to compare differences. The $\mathrm{p}$ value of statistical significance was calculated once the predictive variables were obtained. A p value $<0.05$ was considered as statistically significant. Graph Pad Prism 7.04 ${ }^{\mathrm{TM}}$ software was used for the statistical analysis.

\section{Ethical considerations}

The study was approved by the institutional Review Board of Hospital Británico de Buenos Aires following the Declaration of Helsinki norms and their subsequent revisions.

\section{RESULTS}

A total of 109 patients were included with the following distribution: GI Non-HTN (16 patients), G2 NonHTN (15 patients), GIII Non-HTN (9 patients), GI HTN (26 patients), GII HTN (19 patients) and GIII HTN (24 patients).

GI Non-HTN patients presented with lower waist and neck circumference than GII and GIII Non-HTN patients $(\mathrm{p}<0.05)$ and no significant differences were observed between groups for age and body mass index (BMI) (Table 1).

In the group of patients with HTN, there was greater prevalence of smokers, diabetics (treated with oral hypoglycemic drugs and/or insulin) and patients with dyslipidemia (treated with oral lipid-lowering agents, and/or with total cholesterol, LDL or triglycerides above the normal reference value). There were also significant differences in age, waist circumference, neck circumference and BMI ( $\mathrm{p}<0.05)$, which were greater in the group with moderate-severe OSA (Table 1B).

Overall cardiovascular risk assessed using the ACC/AHA calculator showed that risk was higher in GII and GIII Non-HTN compared with GI Non-HTN patients, same as in GI HTN vs. GII and GIII HTN patients (Tables $1 \mathrm{~A}$ and $\mathrm{B}$ ), though this increase was not statistically significant.

Significant daytime systolic BP differences were found between GI and GIII HTN patients, with increased ABPM in AHI > $15 \mathrm{ev} / \mathrm{h}$ (Table 2).

Blood test results showed a stepwise increase in uric acid and lipid levels in patients without HTN, which were statistically significant depending on OSA severity by AHI. The same pattern was observed in 
hypertensive patients, but the difference was not significant. Fasting baseline blood sugar levels were higher in HTN than in Non-HTN patients, with a stepwise increase $(p<0.05$, Table 3$)$.

Figure 1 shows that OSA patients presented a progressive (albeit not significant) aldosterone increase, with higher morning baseline plasma levels, regardless of whether patients were or not hypertensive. Additionally, we found a stepwise and proportional increase of aldosterone in the group of normotensive patients as OSA severity by AHI increases, $(\mathrm{p}<0.05)$. This pattern was not observed in the group of patients with HTN, in whom plasma aldosterone levels showed a slightly increasing trend according to OSA severity, but without statistically significant differences. (Figure 2).

Renin levels and the aldosterone/renin ratio were assessed to rule out patients with primary hyperaldosteronism (Table 3). Renin values were not significantly different between groups, while the aldosterone/renin ratio evidenced a gradual and growing increase between groups, but without significant differences.

\begin{tabular}{|c|c|c|c|}
\hline Non HTN & GI Non-HTN $(n=16)$ & GII Non-HTN $(n=15)$ & GIII Non-HTN $(n=9)$ \\
\hline Men (\%) & 31 & 33.3 & 77.7 \\
\hline Age (years) & $50.9 \pm 12.4$ & $48.5 \pm 15.8$ & $57.3 \pm 14.7$ \\
\hline Waist circumference $(\mathrm{cm})$ & $89.7 \pm 12$ & $99.7 \pm 17.3$ & $108.6 \pm 14.4$ * \\
\hline Neck circumference (cm) & $35.8 \pm 3.1$ & $39.6 \pm 4.4$ & $40.8 \pm 3.8 * *$ \\
\hline $\mathrm{BMI}(\mathrm{kg} / \mathrm{m} 2)$ & $27.6 \pm 5.5$ & $32.4 \pm 5.8$ & $32.4 \pm 7.6$ \\
\hline Smoking (\%) & $6.2 \%, \mathrm{n}: 1$ & $20 \%, n: 3$ & $11.1 \%, \mathrm{n}: 1$ \\
\hline Diabetes (\%) & $6.2 \%, \mathrm{n}: 1$ & $6.6 \%, \mathrm{n}: 1$ & $11.1 \%, \mathrm{n}: 1$ \\
\hline Dyslipidemia (\%) & $31.2 \%, n: 5$ & $60 \%, \mathrm{n}: 9$ & $100 \%, \mathrm{n}: 9$ \\
\hline ACC/AHA score & 4.5 & 7 & 8.6 \\
\hline
\end{tabular}

Table 1. A. Non-hypertensive population variables.

\begin{tabular}{|c|c|c|c|}
\hline HTN & GI HTN $(n=26)$ & GII HTN $(n=19)$ & GIII HTN $(n=24)$ \\
\hline Men (\%) & 42 & 68.4 & 66.6 \\
\hline Age (years) & $44.4 \pm 12.5$ & $49.3 \pm 12.61$ & $56 \pm 9.6$ * \\
\hline Waist circumference $(\mathrm{cm})$ & $89.4 \pm 13.5$ & $105.1 \pm 9.9$ & $105.5 \pm 13.3$ ** \\
\hline Neck circumference (cm) & $36.9 \pm 4.4$ & $41.6 \pm 3.2$ & $41.4 \pm 3.5$ ** \\
\hline $\mathrm{BMI}(\mathrm{kg} / \mathrm{m} 2)$ & $27.6 \pm 6.7$ & $32.2 \pm 5.8$ & $32.9 \pm 7.3 * *$ \\
\hline Smoking (\%) & $23.1 \%, \mathrm{n}: 6$ & $52.6 \%, \mathrm{n}: 10$ & $41.6 \%, \mathrm{n}: 10$ \\
\hline Diabetes (\%) & $3.8 \%, \mathrm{n}: 1$ & $36.8 \%, \mathrm{n}: 7$ & $29.2 \%, \mathrm{n}: 7$ \\
\hline Dyslipidemia (\%) & $19.2 \%, n: 5$ & $44.4 \%, \mathrm{n}: 8$ & $33.3 \%, n: 8$ \\
\hline ACC/AHA score & 4.9 & 10 & 10.2 \\
\hline
\end{tabular}

Table 1. B. Hypertensive population variables.

Table 2. Office blood pressure and 24-hour ambulatory blood pressure monitoring values

\begin{tabular}{|c|c|c|c|c|c|c|}
\hline & \multicolumn{3}{|c|}{ Without hypertension } & \multicolumn{3}{|c|}{ Hypertension } \\
\hline & $\begin{array}{l}\text { GI Non-HTN } \\
(n=16)\end{array}$ & $\begin{array}{l}\text { GII Non-HTN } \\
(n=15)\end{array}$ & $\begin{array}{l}\text { GIII Non-HTN } \\
\qquad(n=9)\end{array}$ & $\begin{array}{l}\text { GI HTN } \\
(n=26)\end{array}$ & $\begin{array}{l}\text { GII HTN } \\
(n=19)\end{array}$ & $\begin{array}{l}\text { GIII HTN } \\
(n=24)\end{array}$ \\
\hline Office systolic BP & $122 \pm 14$ & $122 \pm 14$ & $122 \pm 14$ & $122 \pm 14$ & $122 \pm 14$ & $122 \pm 14$ \\
\hline Office diastolic BP & $80 \pm 7$ & $80 \pm 7$ & $80 \pm 7$ & $80 \pm 7$ & $80 \pm 7$ & $80 \pm 7$ \\
\hline Daytime systolic ABPM & $118 \pm 7$ & $118 \pm 7$ & $118 \pm 7$ & $118 \pm 7$ & $118 \pm 7$ & $118 \pm 7$ \\
\hline Daytime diastolic ABPM & $74 \pm 6$ & $74 \pm 6$ & $74 \pm 6$ & $74 \pm 6$ & $74 \pm 6$ & $74 \pm 6$ \\
\hline Nighttime systolic ABPM & $106 \pm 9$ & $106 \pm 9$ & $106 \pm 9$ & $106 \pm 9$ & $106 \pm 9$ & $106 \pm 9$ \\
\hline Nighttime diastolic ABPM & $64 \pm 5$ & $64 \pm 5$ & $64 \pm 5$ & $64 \pm 5$ & $64 \pm 5$ & $64 \pm 5$ \\
\hline
\end{tabular}

BP: Blood pressure. ABPM: Ambulatory blood pressure monitoring 


\begin{tabular}{|c|c|c|c|c|c|c|}
\hline \multirow{2}{*}{$\begin{array}{l}\text { Categories } \\
\text { Groups }\end{array}$} & \multicolumn{3}{|c|}{ Non-HTN } & \multicolumn{3}{|c|}{ HTN } \\
\hline & $\begin{array}{l}\text { GI Non-HTN } \\
\quad(n=16)\end{array}$ & $\begin{array}{l}\text { GII Non-HTN } \\
(n=15)\end{array}$ & $\begin{array}{l}\text { GIII Non-HTN } \\
\qquad(n=9)\end{array}$ & $\begin{array}{l}\text { GI HTN } \\
(n=26)\end{array}$ & $\begin{array}{l}\text { GII HTN } \\
(n=19)\end{array}$ & $\begin{array}{l}\text { GIII HTN } \\
(n=24)\end{array}$ \\
\hline Uric acid (mg/dL) & $5 \pm 1 *$ & $5.6 \pm 1$ & $6 \pm 1^{*}$ & $5 \pm 1$ & $5.6 \pm 1.2$ & $5.6 \pm 1.2$ \\
\hline Glucose (mg/dL) & $89 \pm 18$ & $93 \pm 11$ & $95.5 \pm 14$ & $91 \pm 8.5^{* *}$ & $100.6 \pm 30.2^{* *}$ & $101 \pm 30.5^{\star *}$ \\
\hline $\mathrm{Hb} 1 \mathrm{Ac}(\%)$ & $5.5 \pm 0.3$ & $5.5 \pm 0.6$ & $5.7 \pm 0.66$ & $5.4 \pm 0.25$ & $5.9 \pm 1.6$ & $5.9 \pm 1.6$ \\
\hline Triglycerides (mg/dL) & $91 \pm 33$ & $129.5 \pm 55$ & $127.2 \pm 51$ & $140 \pm 106$ & $142 \pm 105$ & $151.8 \pm 73.6$ \\
\hline Total cholesterol (mg/dL) & $173 \pm 30 * *$ & $201 \pm 35^{\star *}$ & $201 \pm 30 * *$ & $190 \pm 42$ & $194 \pm 38$ & $196 \pm 38$ \\
\hline Creatinine (mg/dL) & $0.8 \pm 0.1$ & $0.8 \pm 0.1$ & $0.85 \pm 0.12$ & $0.8 \pm 0.1$ & $0.9 \pm 0.13$ & $0.9 \pm 0.12$ \\
\hline Aldosterone (pg/mL) & $120 \pm 88$ & $132.4 \pm 98.3$ & $138.4 \pm 98.4$ & $128 \pm 61.2$ & $130 \pm 76$ & $133 \pm 76$ \\
\hline Renin (ngA1/mL/h) & $1.9 \pm 0.9$ & $1.7 \pm 1.3$ & $1.4 \pm 0.5$ & $2.2 \pm 1.5$ & $1.8 \pm 1.0$ & $1.4 \pm 0.8$ \\
\hline Aldosterone/renin ratio & $8.7 \pm 5.7$ & $9 \pm 5.1$ & $12.7 \pm 7.9$ & $2.3 \pm 1.4$ & $10.3 \pm 7$ & $11 \pm 6.5$ \\
\hline
\end{tabular}

* $p<0.05$ between two groups and ** $p<0.05$ for GI Non-HTN vs. GII and GIII.

Fig. 1. Mean plasma aldosterone values related with HTN diagnosis and $\mathrm{AHI}>5 \mathrm{ev} / \mathrm{h}$ in respiratory poligraphy. Mean baseline aldosterone was higher in hypertensive patients $(139.1 \pm 88.6$ vs. 127.4 \pm 83.3 ).

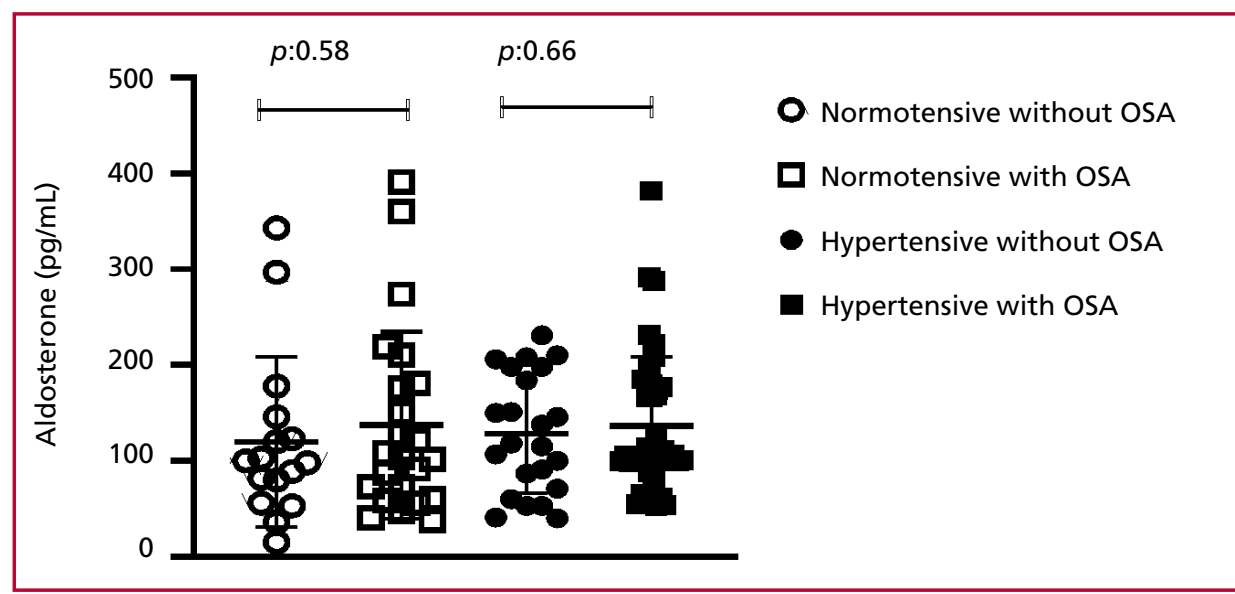

OSA: Obstructive sleep apnea

\section{DISCUSSION}

There is a relationship between HTN and OSA and both increase morbidity and mortality; it is therefore relevant to understand the interaction between both pathologies.

This study suggests that OSA could be linked to modifications in aldosterone values independently of HTN.

Interestingly, a stepwise increase was observed between OSA and aldosterone values in Non-HTN patients $(\mathrm{p}<0.05)$, while in the HTN group a growing trend was seen but without statistically significant differences. This could be due to two possible reasons: the first might be statistical, since, to obtain statistical significance, the sample size with these values would be 266 patients with a zeta power of 1.96 , and the second could be that baseline aldosterone values in hypertensive patients would correspond to a different physiopathogenic pathway.

Studies analyzing the role of aldosterone in OSA were generally carried out in patients with severe or resistant HTN, or else, in hypertensive populations treated with drugs (even anti-aldosterone agents) which could have affected the interpretation. (16, 20)

The results of independent cardiovascular risk factors, as waist circumference, neck circumference, BMI and laboratory glycemic and lipid profiles are possibly reflected as a whole in the ACC/AHA score, leading us to the conclusion that hypertensive patients with OSA present higher cardiovascular risk. $(19,33)$

A discrete elevation in office $\mathrm{BP}$ as in daytime and nighttime ABPM values was observed in hypertensive patients, as AHI-assessed severity increased. Blood pressure and ABPM values consistent with diagnostic criteria of HTN were associated with higher aldosterone levels than those found in the Non-HTN group.

The increase pattern of plasma aldosterone showed a proportional and stepwise significant trend in normotensive patients dependent on OSA severity. Thus, we found that aldosterone increases with a gradual slope in the normotensive group, which is attributable to a dose-response biological phenomenon, possibly as 


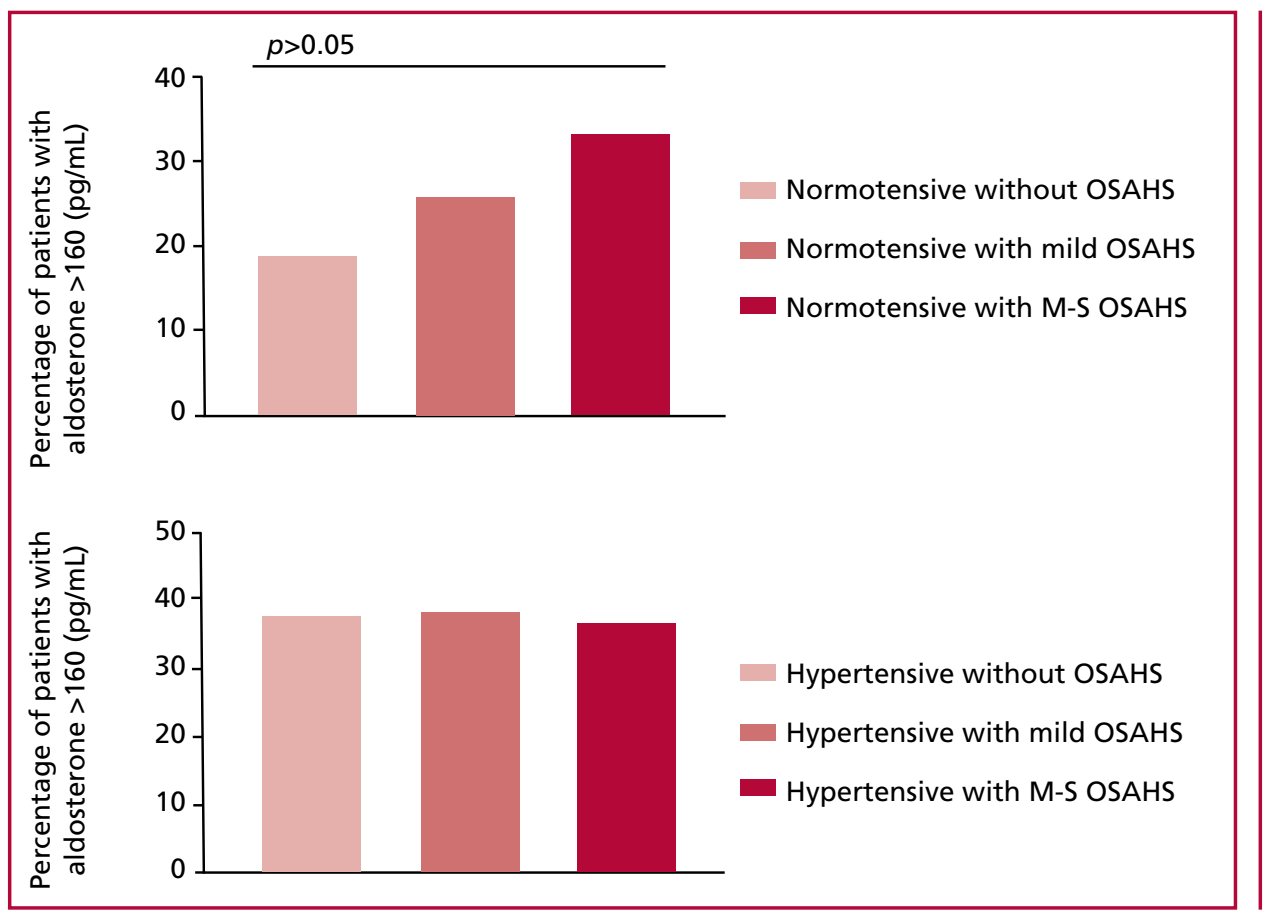

Fig. 2. Distribution according to plasma aldosterone values $>160 \mathrm{pg} / \mathrm{dL}$ (reference value).

OSAHS: Obstructive sleep apnea and hypopnea syndrome. M-S: Moderate-severe.

a consequence of increased AHI and the degree of nocturnal hypoxemia.

In our population, the percentage of patients with baseline aldosterone $>160 \mathrm{ng} / \mathrm{ml}$ was $35 \%$ with $\mathrm{AHI}$ $>15 \mathrm{ev} / \mathrm{h}$ versus $40 \%$ in the HTN group. In agreement with the Birmingham group hypothesis, it is possible that in OSA patients there is an important role of aldosterone and that hydrosaline retention, with fluid displacement from the tissues to the neck, is associated with AHI severity. (20) We did not perform physiological measurements of fluid displacement in these patients and this represents, to a certain extent, a limitation of the study.

Additionally, the strengths of the present analysis lie in the definition of HTN using a systematic ABPM reading together with a standardized technique for sleep studies by experts in sleep medicine, $(17,19)$ and to the fact that we included untreated (naïve) patients at the time of assessment, of whom there is scarce information. Studies with a larger number of subjects are necessary to confirm our findings, which must be seen as generators of hypotheses. The small sample size may cause a significant beta error which should be corrected with the continuation of this and other studies along the same line of research.

Finally, our results show a proportional increase of aldosterone, blood glucose and cardiovascular risk values as the severity of sleep apnea increases.

This investigation received no financial support.
Conflicts of interest

None declared.

(See authors' conflicts of interest forms on the website/ Supplementary material).

\section{REFERENCES}

1. Pratt-Ubunama MN, Nishizaka MK, Boedefeld RL, Cofield SS, Harding SM, Calhoun DA. Plasma aldosterone is related to severity of obstructive sleep apnea in subjects with resistant hypertension. Chest 2007;131:453-9. https://doi.org/10.1378/chest.06-1442

2. Pedrosa RP, Drager LF, Gonzaga CC, Sousa MG, de Paula LK, Amaro AC, et al. Obstructive sleep apnea: the most common secondary cause of hypertension associated with resistant hypertension. Hypertension 2011;58:811-7. https://doi.org/10.1161/HYPERTENSIONAHA.111.179788

3. br, Skatrud J. Prospective study of the association between sleep-disordered breathing and hypertension. N Engl J Med 2000;342:1378-84. https://doi.org/10.1056/NEJM200005113421901 4. Marín M, Fábregues G, Rodríguez P et al. Registro Nacional de Hipertensión Arterial. Conocimiento, tratamiento y control de la hipertensión arterial. Estudio RENATA. Rev Argent Cardiol 2012;80:121-9.

5. Tufik S, Santos-Silva R, Taddei JA, Bittencourt LR. Obstructive sleep apnea syndrome in the Sao Paulo Epidemiologic Sleep Study. Sleep Med 2010;11:441-6. https://doi.org/10.1016/j.sleep.2009.10.005 6. Rey de Castro Mujica J, Rosales Mayor E. Evaluation of the relationship be-tween obstructive sleep apnea and hypertension. Rev Med Hered 2009;20:123-32.

7. Duran J, Esnaola S, Rubio R, Iztueta A. Obstructive sleep apneahypopnea and related clinical features in a population-based sample of subjects aged 30 to $70 \mathrm{yr}$. Am J Respir Crit Care Med 2001;163:6859. https://doi.org/10.1164/ajrccm.163.3.2005065

8. Kario K. Obstructive sleep apnea syndrome and hypertension: mechanism of the linkage and 24-h blood pressure control. Hypertens Res 2009;32:537-41. DOI 10.1038/hr.2009.73

9. Floras JS. Hypertension and Sleep Apnea. Can J Cardiol. 2015;31:889-97. https://doi.org/10.1016/j.cjca.2015.05.003 
10. Parati G, Lombardi C, Hedner J, Bonsignore MR, Grote L, Tkacova $\mathrm{R}$, et al. Position paper on the management of patients with obstructive sleep apnea and hypertension: joint recommendations by the European Society of Hypertension, by the European Respiratory Society and by the members of European COST (COoperation in Scientific and Technological research) ACTION B26 on obstructive sleep apnea. J Hypertens 2012;30:633-46. https://doi.org/10.1097/ HJH.0b013e328350e53b.

11. Selim B, Won C, Yaggi HK. Cardiovascular consequences of sleep apnea. Clin Chest Med 2010;31:203-20. https://doi.org/10.1016/j. ccm.2010.02.010

12. Barashi NS, Ruiz R, Marin L, Ruiz P, Amado S, Ruiz A, et al. Síndrome de apnea/hipopnea obstructiva del sueño y su asociación con las enfermedades cardiovasculares. Rev Colomb Cardiol 2015;22:81-7. 13. Gaddam K, Pimenta E, Thomas SJ, Cofield SS, Oparil S, Harding SM, et al. Spironolactone reduces severity of obstructive sleep apnoea in patients with resistant hypertension: a preliminary report. J Hum Hypertens 2010;24:532-7. https://doi.org/10.1038/jhh.2009.96 14. Cortelli P, Lombardi C, Montagna P, Parati G. Baroreflex modulation during sleep and in obstructive sleep apnea syndrome. Auton Neurosci 2012;169:7-11. https://doi.org/10.1016/j.autneu.2012.02.005

15. Pezzi P, Fernández D, Caruso G. Fisiopatología de la hipertensión arterial en los desórdenes respiratorios del sueño. Capítulo 55. Libro de hipertensión de la SAHA. Disponible en: http://www.saha.org.ar/ formacion/libro. Consultado: 12/09/2019.

16. Tamisier R, Pepin JL, Remy J, Baguet JP, Taylor JA, Weiss JW, et al. 14 nights of intermittent hypoxia elevate daytime blood pressure and sympathetic activity in healthy humans. Eur Respir J 2011;37:119-28. https://doi.org/10.1183/09031936.00204209

17. Borsini E, Blanco M, Bosio M, Fernando DT, Ernst G, Salvado A. "Diagnosis of sleep apnea in network" respiratory polygraphy as a decentralization strategy. Sleep Sci 2016;9:244-8. https://doi. org/10.1016/j.slsci.2016.10.009

18. Borsini E, Ernst G, Salvado A, Bosio M, Chertcoff J, Nogueira F, et al. Utility of the STOP-BANG components to identify sleep apnea using home respiratory polygraphy. Sleep Breath. 2015;19:1327-33. https://doi.org/10.1007/s11325-015-1174-2

19. Borsini E, Blanco M, Bosio M, Schrappe M, Ernst G, Nosetto D, et al. Prevalence of sleep apnea and cardiovascular risk factors in patients with hypertension in a day hospital model. Clin Exp Hypertens 2018;40:231-7. https://doi.org/10.1080/10641963.2017.1356841 20. Dudenbostel T, Calhoun DA. Resistant hypertension, obstructive sleep apnoea and aldosterone. J Hum Hypertens 2012;26:281-7. https://doi.org/10.1038/jhh.2011.47

21. Yang L, Zhang H, Cai M, Zou Y, Jiang X, Song L, et al. Effect of spironolactone on patients with resistant hypertension and obstructive sleep apnea. Clin Exp Hypertens 2016;38:464-8. https://doi.org/ 10.3109/10641963.2015.1131290

22. Lattimore JD, Celermajer DS, Wilcox I. Obstructive sleep apnea and cardiovascular disease. J Am Coll Cardiol 2003;41:1429-37. https://doi.org/10.1016/s0735-1097(03)00184-0

23. Erdem F, Cakir U, Yildirim O, Alcelik A, Donmez I, Tuman TC, et al. A new diagnostic tool for masked hypertension: impaired sleep quality. Arch Med Sci. 2016;12:1207-13. https://doi.org/10.5114/ aoms.2015.51177

24. Kario K. Obstructive sleep apnea syndrome and hypertension: ambulatory blood pressure. Hypertens Res 2009;32:428-32. https:// doi.org $/ 10.1038 / \mathrm{hr} .2009 .56$

25. Barceló A, Pierola J, Esquinas C, de la Pena M, Arque M, Alonso-Fernández $\mathrm{A}$, et al. Relationship between aldosterone and the metabolic syndrome in patients with obstructive sleep apnea hypopnea syndrome: effect of continuous positive airway pressure treatment. PLoS One 2014;9:e84362. https://doi.org/10.1371/journal. pone.0084362

26. Friedman O, Bradley TD, Chan CT, Parkes R, Logan AG. Relationship between overnight rostral fluid shift and obstructive sleep apnea in drug-resistant hypertension. Hypertension 2010;56:107782. https://doi.org/10.1161/HYPERTENSIONAHA.110.154427

27. Ke X, Guo W, Peng H, Hu C, Zhang H, Peng C, et al. Association of aldosterone excess and apnea-hypopnea index in patients with resistant hypertension. Sci Rep 2017;7:45241. https://doi.org/10.1038/ srep 45241

28. Svatikova A, Olson LJ, Wolk R, Phillips BG, Adachi T, Schwartz GL, et al. Obstructive sleep apnea and aldosterone. Sleep 2009;32:1589-92. https://doi.org/10.1093/sleep/32.12.1589

29. Majul C, Marín M. Consenso de Hipertensión Arterial Consejo Argentino de Hipertensión Arterial "Dr. Eduardo Braun Menéndez". Rev Argent Cardiol 2013;81(Supl. 2):1-72.

30. Mancia G, Fagard R, Narkiewicz K, Redon J, Zanchetti A, Bohm M, et al. $2013 \mathrm{ESH} / \mathrm{ESC}$ Guidelines for the management of arterial hypertension: the Task Force for the management of arterial hypertension of the European Society of Hypertension (ESH) and of the European Society of Cardiology (ESC). J Hypertens. 2013;31:1281357. https://doi.org/10.1097/01.hjh.0000431740.32696.cc

31. Collop NA, Anderson WM, Boehlecke B, Claman D, Goldberg R, Gottlieb DJ, et al. Clinical guidelines for the use of unattended portable monitors in the diagnosis of obstructive sleep apnea in adult patients. Portable Monitoring Task Force of the American Academy of Sleep Medicine. J Clin Sleep Med 2007;3:737-47.

32. Berry RB, Budhiraja R, Gottlieb DJ, Gozal D, Iber C, Kapur VK, et al. Rules for scoring respiratory events in sleep: update of the 2007 AASM Manual for the Scoring of Sleep and Associated Events. Deliberations of the Sleep Apnea Definitions Task Force of the American Academy of Sleep Medicine. J Clin Sleep Med 2012;8:597-619. https://doi.org/10.5664/jesm. 2172

33. Goff DC, Jr., Lloyd-Jones DM, Bennett G, Coady S, D'Agostino RB, Gibbons R, et al. 2013 ACC/AHA guideline on the assessment of cardiovascular risk: a report of the American College of Cardiology/American Heart Association Task Force on Practice Guidelines. Circulation 2014;129(25 Suppl 2):S49-73. https://doi.org/10.1161/01. cir.0000437741.48606.98 